\title{
Distribution of chronic or recurrent headache in children and adolescents in two studies - epidemiological study and clinical-based study
}

\author{
Pacheva $\mathbf{I}^{1 *}$, I. Ivanov $I^{1}$, Milanov $I^{2}$ and Stefanov $\mathbf{R}^{3}$ \\ ${ }^{1}$ Department of Pediatrics and Medical Genetics, Medical University, Plovdiv, Bulgaria \\ ${ }^{2}$ St. Naum University Hospital of Neurology and Psychiatry, Sofia, Bulgaria \\ ${ }^{3}$ Department of Social medicine, Medical University, Plovdiv, Bulgaria
}

\begin{abstract}
An increasing incidence and significance of chronic or recurrent headache $(\mathrm{CRH})$ in children and adolescents is observed.

Aim: To compare the distribution of $\mathrm{CRH}$ types in epidemiological and clinical studies.

Material and methods: The epidemiological study included 1029 pupils aged 7-17yrs attending three different types of schools in the Plovdiv region. Inclusion criterion was at least two episodes of headache in the last year. Exclusion criteria were headache only during infections or refusal to fill- in questionnaire. The study was conducted in four steps: I- questionnaire; II- clinical interview, physical and neurological examination, III- additional investigations, IV- classification according to IHDC-II-2004. The clinical study included 203 newly diagnosed patients with CRH aged 0-17 years admitted to the Neuropediatric Ward or treated in an outpatient clinic during years 2002-2006. The clinical study started from step II.

Results: Tension type headache (TTH) was the most frequent type of CRH in the epidemiological study - 42,5\% of CRH, followed by migraine - 32\%. Secondary headache comprised $2,7 \%$ of CRH. In the clinical setting, however, migraine was the commonest type of CRH - 46,8\%, followed by TTH - 29,6\%, and secondary headache $-7,4 \%$. There were no significant differences between in- and outpatient case frequencies.

Conclusions: TTH is the most prevalent headache type in children and adolescents. Migraine and secondary headache are more frequent in clinical settings than in epidemiological studies, probably because they induce search of medical help more frequently than TTH. Distribution of CRH types was similar in in- and outpatient neuropediatric practices.
\end{abstract}

\section{Introduction}

The incidence of chronic or recurrent headache $(\mathrm{CRH})$ in children and adolescents is increasing in the recent years and becomes a significant social problem, but the data in the literature are variable [1-7]. Different methodological attitudes could be a reason for some controversal data in different studies. The prevalence of various headache types was established in epidemiological studies, but the frequency of headache types in clinical practice resulted from patients'refering to neurological consultation.

\section{Patients and methods}

The present investigation consisted of two subsets - an epidemiological study and a clinical study.

\section{Epidemiological study}

Epidemiological study was a school - based study among 7- to 17 year-old students in the schools of Plovdiv region of Bulgaria. Plovdiv is the second city of Bulgaria. Random sampling was made among the public schools from urban and rural districts of Plovdiv. A total of 1063 pupils aged 7-17 years were randomly selected from three different schools.

Inclusion criterion was at least two episodes of headache during the last year. Exclusion criteria were: 1 . Headache occurring only during acute infections; 2. Withdrawal of informed consent.

The study was approved by the Plovdiv Medical University Ethics Committee and by the school authorities. Confidentiality was guaranteed to all pupils and their parents.

A total of 1029 pupils (96,8\% of the selected) completed the study.

The epidemiological study was conducted in four steps.

\section{I step: Questionnaire}

All selected students received a specially designed questionnaire from their teachers or the school nurse/ physician. It contained 21 questions inquiring all characteristic features of headache syndromes

Correspondence to: Iliyana Pacheva, Department of Pediatrics and Medical Genetics, Medical University - Plovdiv, 15A Vasil Aprilov str, 4000 Plovdiv, Bulgaria, Tel: +359 32 602251, Fax: +359 32 602547, E-mail: inapatcheva@hotmail.com

Key words: chronic recurrent headache, children, adolescent, epidemiological study, clinical-based study

Received: October 01, 2016; Accepted: October 22, 2016; Published: October 26,2016 
according to the ICHD-II diagnostic criteria. It was also used to collect information about additional factors like headache frequency, family history, possible triggering factors, associated conditions or diseases, etc. Students above the age of 10 filled in the questionnaire on their own. The others did it at home with their parents and then returned it to their teacher.

\section{II step: Clinical interview, physical and neurological examination}

It was performed by a team of three headache experts lead by a pediatric neurologist in the month after step I. The interview followed the structure of the questionnaire and gave additional explanation of the questions, which had been misunderstood. In case of discrepancy between the answers in the questionnaire and during the interview the latter was accepted as correct. Physical examination focused on height, weight, head circumference, rash, pigmentations and depigmentations; nasal obstruction, palpable pain over nasal sinuses, auscultation for murmurs over the neck and temporal bone, heart auscultation, blood pressure. Neurological examination included evaluation of cranial nerves, muscle tone and strength, reflexes, sensation, coordination and gait.

\section{III step: Additional consultations and investigations}

Ophthalmologic, otorhinolaringologic, EEG, Doppler sonography, imaging (CT or MRI) and laboratory investigations, such as $\mathrm{CBC}$, electrolytes, hormones, were performed in cases where secondary headache was suspected.

\section{IV step: Classification}

Each case with headache was classified according to the diagnostic criteria of ICHD - II - 2004 year.

\section{Clinical study}

It included 203 newly diagnosed patients with chronic or recurrent headache from the 2509 children that were admitted to the Pediatric Neurology Ward at Plovdiv Medical University Hospital, or treated as outpatients in the five-year period between 2002 and 2006. The clinical study used the same inclusion and exclusion criteria as the epidemiological one. It started from step II and progressed to step IV of the previously described study design.

Children and adolescents were distributed in three age groups: 0-6 years; 7-13 years; $14-17$ years.

After classification of the headache by type, patients from the epidemiological and clinical studies with identical headache types were analyzed.

The definitions of headache characteristics and the differentiation of clinical characteristics are listed in

\section{Appendix 1}

\section{Statistical methods}

Parametric and non parametric, correlative, linear and nonlinear regressive analyses were applied using SPSS 11 software.

Different tests of statistical significance were applied as appropriate: t-test, Fisher exact test, chi-square, Kolmogorov-Smirnov test and Kruskal-Wallis $\mathrm{H}$ test ( $\mathrm{p}<0.05$ was considered statistically significant).

\section{Results}

The prevalence of various headache types is presented in table 1.

The ratio of TTH was the highest in epidemiological study $-42,5 \%$ of $\mathrm{CRH}$, followed by migraine $-33,3 \%$ of $\mathrm{CRH}$. Secondary headache comprised $2,7 \%$ of $\mathrm{CRH}$.

Patients with CRH comprised 6,6\% of newly diagnosed patients in the Pediatric Neurology Ward and 9,9\% of consulted in the out-patient clinics.

The distribution of various CRH types in clinical-based study is presented on fig.1. The distribution of headache types in out-patient and in-patient practices are illustrated on fig.2, but the distribution according to age and sex is presented in table 2.

In clinical based study the most common type of CRH was migraine $(46,8 \%)$, followed by TTH $(29,6)$. Secondary headache took the third place $(7,4 \%)$. The other headache types comprised: $2,5 \%$ other primary headache, 5,6\% - mixed headache,3,9\% - overlapping headache and 4,4\% - non-classifiable headache.

Patients aged 7-13 years prevailed in clinical-based study (61,9\% of patients with $\mathrm{CRH}$ in out-patient clinics and $54,4 \%$ of patients with CRH in in-patient clinic) (Table 2).

Comparing the type of pediatric neurology practice: in- and outpatient clinic, there were no significant differences in headache type distribution. Migraine was the most common headache type in both practices, followed by TTH and there was no significant difference $(41,1 \%$ vs $51,3 \% ; p>0,05)$. Five patients were with other primary

Table 1. The prevalence of various types of CRH in epidemiological study.

\begin{tabular}{|c|c|c|c|c|c|c|c|c|c|}
\hline \multirow{3}{*}{$\begin{array}{l}\text { type } \\
\text { headache }\end{array}$} & \multicolumn{3}{|c|}{ 7-13years } & \multicolumn{3}{|c|}{ 14-17years } & \multicolumn{3}{|c|}{ All } \\
\hline & \multicolumn{3}{|c|}{$\mathrm{n}=544$} & \multicolumn{3}{|c|}{$n=485$} & \multicolumn{3}{|c|}{$n=1029$} \\
\hline & $\mathrm{n}$ & $\%$ & $S p$ & $\mathrm{n}$ & $\%$ & $S p$ & $\mathrm{n}$ & $\%$ & $S p$ \\
\hline Migraine & 55 & 10,1 & 1,3 & 82 & 16,9 & 1,7 & 137 & 13,3 & 1 \\
\hline TTH & 63 & 11,6 & 1,4 & 112 & 23,1 & 1,9 & 175 & 17 & 1,2 \\
\hline Overlapping - M/TTH & 16 & 2,9 & 0,7 & 24 & 4,9 & 1 & 40 & 3,9 & 0,6 \\
\hline Mixed & 9 & 1,7 & 0,6 & 17 & 3,5 & 0,8 & 26 & 2,5 & 0,5 \\
\hline Other primary & 2 & 0,4 & 0,3 & 1 & 0,2 & 0,2 & 3 & 0,3 & 0,2 \\
\hline Secondary & 3 & 0,6 & 0,3 & 8 & 1,6 & 0,6 & 11 & 1,1 & 0,3 \\
\hline Non-classified & 9 & 1,7 & 0,6 & 11 & 2,3 & 0,7 & 20 & 1,9 & 0,4 \\
\hline $\begin{array}{l}\text { Cronic / } \\
\text { Recurrent } \\
\text { ( CRH ) }\end{array}$ & 157 & 28,9 & 1,9 & 255 & 52,6 & 2,3 & 412 & 40 & 1,5 \\
\hline
\end{tabular}


Table 2. Age and sex distribution of various headache types in the out-patient and in-patient clinics.

\begin{tabular}{|c|c|c|c|c|c|c|c|c|c|c|c|c|}
\hline \multirow{3}{*}{$\begin{array}{l}\text { Type } \\
\text { headache }\end{array}$} & \multicolumn{4}{|c|}{ 0-6years } & \multicolumn{4}{|c|}{ 7-13years } & \multicolumn{4}{|c|}{ 14-17years } \\
\hline & \multirow{2}{*}{$\begin{array}{c}\text { M } \\
\mathbf{n}=14 \\
\mathbf{n}\end{array}$} & \multirow{2}{*}{$\begin{array}{c}\mathbf{F} \\
\mathrm{n}=12 \\
\mathrm{n}\end{array}$} & \multicolumn{2}{|c|}{$\begin{array}{c}\text { All } \\
n=26\end{array}$} & \multirow{2}{*}{$\begin{array}{c}\begin{array}{c}M \\
n=56\end{array} \\
n\end{array}$} & \multirow{2}{*}{$\left.\begin{array}{c}F \\
n=63\end{array}\right)$} & \multicolumn{2}{|c|}{$\begin{array}{c}\text { All } \\
n=119\end{array}$} & \multirow{2}{*}{$\begin{array}{c}\begin{array}{c}\text { M } \\
\mathbf{n}=\mathbf{2 5}\end{array} \\
\mathbf{n}\end{array}$} & \multirow{2}{*}{$\begin{array}{c}\mathbf{F} \\
\mathbf{n}=\mathbf{3 3} \\
\mathbf{n}\end{array}$} & \multicolumn{2}{|c|}{$\begin{array}{c}\text { All } \\
n=58\end{array}$} \\
\hline & & & $\mathbf{n}$ & $\%$ & & & n & $\%$ & & & $\mathbf{n}$ & $\%$ \\
\hline \multicolumn{13}{|l|}{ In-patient clinic } \\
\hline Migraine & 2 & 1 & 3 & 27 & 13 & 9 & 22 & 44,9 & 8 & 4 & 12 & 37,5 \\
\hline TTH & 0 & 2 & 2 & 22,2 & 9 & 9 & 18 & 36,7 & 2 & 5 & 7 & 21,9 \\
\hline Over-lapping & 0 & 0 & 0 & 0 & 1 & 0 & 1 & 2 & 2 & 2 & 4 & 12,5 \\
\hline mixed & 0 & 0 & 0 & 0 & 0 & 2 & 2 & 4,1 & 2 & 0 & 2 & 6,3 \\
\hline Other primary & 0 & 0 & 0 & 0 & 0 & 0 & 0 & 0 & 1 & 1 & 2 & 6,3 \\
\hline Secondary & 0 & 3 & 4 & 44,4 & 3 & 1 & 4 & 8,2 & 2 & 1 & 3 & 9,4 \\
\hline Non-classifiable & 1 & 0 & 1 & 11,1 & 1 & 1 & 2 & 4,1 & 0 & 2 & 2 & 6,3 \\
\hline All & 3 & 6 & 9 & 100 & 27 & 22 & 49 & 100 & 17 & 15 & 32 & 100 \\
\hline \multicolumn{13}{|l|}{ Out-patient clinic } \\
\hline Migraine & 7 & 1 & 8 & 47,1 & 17 & 20 & 37 & 52,9 & 4 & 9 & 13 & 50 \\
\hline TTH & 3 & 2 & 5 & 29,4 & 7 & 9 & 16 & 22,9 & 4 & 8 & 12 & 46,2 \\
\hline Over-lapping & 0 & 0 & 0 & 0 & 1 & 2 & 3 & 4,3 & 0 & 0 & 0 & 0 \\
\hline mixed & 0 & 0 & 0 & 0 & 2 & 5 & 7 & 10 & 0 & 0 & 0 & 0 \\
\hline Other primary & 0 & 1 & 1 & 5,9 & 1 & 1 & 2 & 2,8 & 0 & 0 & 0 & 0 \\
\hline secondary & 0 & 1 & 1 & 5,9 & 1 & 3 & 4 & 5,7 & 0 & 0 & 0 & 0 \\
\hline Non-classifiable & 1 & 1 & 2 & 11,8 & 0 & 1 & 1 & 1,4 & 0 & 1 & 1 & 3,8 \\
\hline All & 11 & 6 & 17 & 100 & 29 & 41 & 70 & 100 & 8 & 18 & 26 & 100 \\
\hline
\end{tabular}

headache: 2 with idiopathic stabbing headache; 1 with cluster headache; 1 with hemicrania continua, 1 with new daily headache, i.e. idiopathic headache was the next common primary type, following migraine and TTH.

Secondary headache comprised higher percentage in the in-patient practice, but without significant difference $(11,1 \%$ vs $4,1 \%$; $>0,05)$ (Figure 1,2).

\section{Discussion}

Our patients with CRH comprised lower percentage of all patients in pediatric neurology practice ( less than $10 \%$ ), compared with data of Moore et Shevel - 24\% (8). Probably headache was the more frequent reason for seeking specialized medical help in their country. According to the age, patients aged 7-13 years prevailed in our clinical-based study, although the prevalence of CRH is higher in 14-17 year- old students. The reason for this could be either neglect of the headache from 14-17 year-old adolescents or seeking adult neurologists.

TTH was the most frequent headache type in epidemiological study $-42,5 \%$ of $\mathrm{CRH}$, followed by migraine $-33,3 \%$ of CRH.

In clinical pediatric neurology practice, in contrast to the epidemiological study, migraine was the leading type of $\mathrm{CRH}-46,8 \%$, followed by TTH - 29,6\%. Secondary headache comprised larger portion of $\mathrm{CRH}-7,4 \%$, compared to epidemiological study $-2,7 \%$, which is influenced probably by more severe cases examined in the pediatric neurology practice.

Migraine prevailed among headache types of CRH in all age groups in pediatric neurology practices, followed by TTH, but there was statistical significant difference only in the age of $7-13$ years $(\mathrm{p}<0,01)$. Comparing the three age groups, there were no significant differences in the ratio of various headache types $(p>0,05)$, although the percentage of TTH increased with age in the out-patient clinic: $22,9 \%$ in the age of $7-13$ years to $46,2 \%$ in the age of $14-17$ years $(\mathrm{p}<0.05)$.

In clinical based-study secondary headache comprised the highest percentage below 7 years of age, but without significant difference

\section{The distributionof $\mathrm{CRH}$ types inclinical-basedstudy}
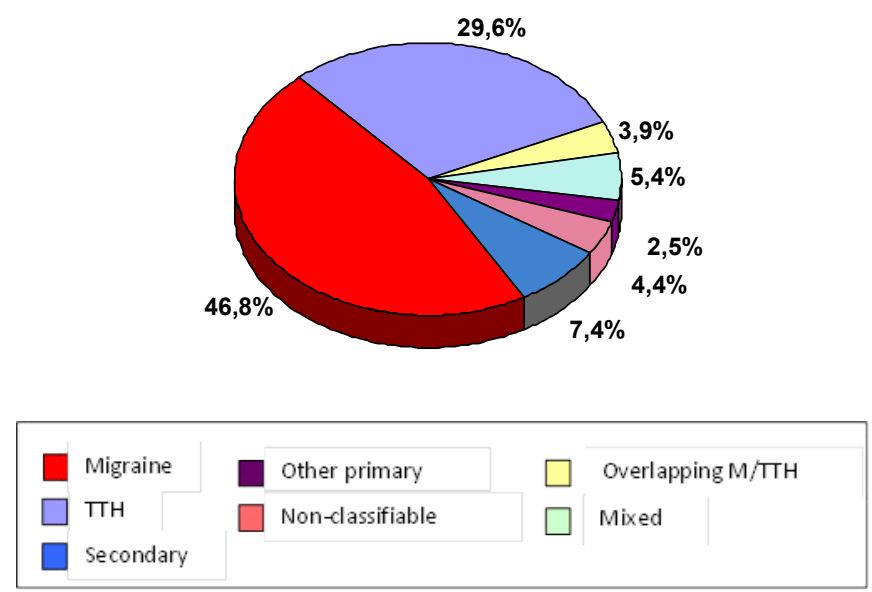

Figure 1. Distribution of various headache types in pediatric neurology practice.

( $\mathrm{p}>0,05): 15,4 \%$ of $\mathrm{CRH}$ in the age $0-6$ years, $7,5 \%$ in the age $7-13$ years and $8,3 \%$ in the age $14-17$ years. It could be suggested that secondary headache comprises higher percentage in the age under seven, because of lower frquency of primary headache.

Similar percentage of secondary headache in outpatients under the age of 6 years was found by Raieli et al in a Headache center [9]. They also found higher ratio of idiopathic stabbing headache in this age group, comparing with older children [9,10]. Raieli et al. [9] and Balottin et al. [11] diagnosed TTH more commonly than migraine in the age below 6 years, while there were no statistical significant difference between both headache types in our study, but migraine prevailed.

Non-classifiable headache was higher percentage in small age group: $11,5 \%$ of patients aged $0-6$ years, compared with $2,5 \%$ in the group $7-13$ years and $5,2 \%$ in the age $14-17$ years, but $p<0,05$. It could 


\section{The distribution of CRH types in out - patient practice}
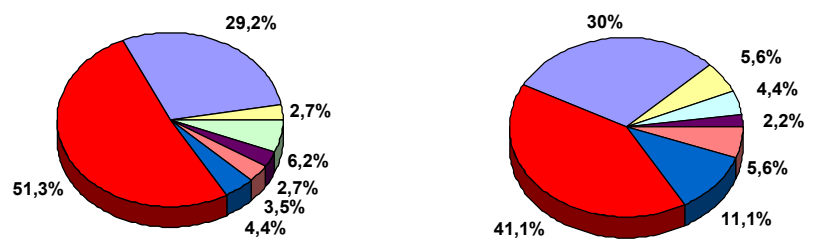

$\begin{array}{|lll|}\square \text { Migraine } & \square \text { Other primary } & \square \text { OverlappingM/TTH } \\ \square \text { TाH } & \square \text { Non-classifiable } & \square \text { Mixed } \\ \square \text { Secondary } & & \end{array}$

Figure 2. Distribution of various headache types in pediatric neurology practices.

be explained by the difficulty of children under the age of seven to describe the characteristics of headache, therefore it will be better to use drawing of headache characteristics in small age group.

There were no statistical significant sex differences in the distribution of headache types in clinical-based study.

Our results for headache types distribution in clinical-based study were similar to data of Gallai V et al. (including 719 patients of 21 Italian headache centers), and other authors [12-16]. There were studies with higher percentage of migraine - Pascual et Berciano [17] pointed out $93 \%$ and only $4 \%$ TTH in outpatients, aged 7-14 years; Lima et al. found migraine in higher percentage $-72 \%$ of outpatients with $\mathrm{CRH}$, aged 2-15 years [5]. These authors did not mention mixed headache. In contrast to other authors, Seshia diagnosed mixed headache and chronic daily headache in high percentage - $32 \%$, respectively $31 \%$ of patients with $\mathrm{CRH}$ in pediatric neurology practice and lower percentage of migraine $-38 \%$ and TTH $-18 \%[18,19]$. These differences probably were explained by the fact that his clinic was specialized headache center and the patients had longer history of headache.

We did not find any statistical significant differences in the distribution of CRH types between both clinics: out- and in- patient, despite the higher percentage of secondary headache in in-patient's group, probably result of more frequent refering of patients with secondary headache to a hospital. We did not find studies, comparing in- and outpatient's clinics.

\section{Conclusion}

- TTH was the most prevalent headache type in children and adolescents.

- Migraine and secondary headache were more frequent in clinical pediatric neurology practice than in epidemiological study. Therefore they were more frequent reasons for seeking special medical help. TTH is probably neglected by parents.

- Distribution of CRH types was similar in out- and in-patient pediatric neurology practice. Migraine comprised highest percentage in all age groups, followed by TTH. Secondary and nonclassifiable headache could comprised higher percentage in the age below 6 years.

- The established differences in the distribution of CRH types between epidemiological study and clinical-based study could explain existing variable data in the literature about occurrence of different headache types in children and adolescents.

\section{Appendix 1}

Definition and categorization of headache characteristics:

Types of headache are classified according to the International Classification of Headache Disorders - II - 2004 year.

"Mixed headache" meant coexistence of episodes of TTH and migraine.

"Overlapping headache" covered cases, which could be classified as either probable MWA or probable ETTH.

"Other headache" included headaches different from only migraine, only TTH and secondary headache.

Localization of headache was differentiated as unilateral, bifrontal, bitemporal, diffuse, occipital, and other.

"Migrainous location" included unilateral, bifrontal or bitemporal location

Pain intensity was defined as mild, moderate, severe and different.

The quality of pain was differentiated as pulsating, pressingtightening, stabbing, undetermined, and different. Non pulsating quality included all qualities different from pulsating.

The aggravation of pain by daily physical activity was coded as "yes", "no" or "sometimes". "Yes" and "sometimes" were summarized as a positive answer.

Associated symptoms as nausea, vomiting, photophobia, phonophobia, vertigo/lightheadedness were coded separately as "yes", "no" or "sometimes". "Yes" and "sometimes" were summarized as a positive answer.

Positive first or second line family history of migraine was noted as "yes" or "no".

\section{References}

1. Abu-Arefeh I, Russell G (1994) Prevalence of headache and migraine in schoolchildren. BMJ 309: 765-769. [Crossref]

2. Ando N, Fujimoto S, Ishikawa T, Teramoto J, Kobayashi S, et al. (2007) Prevalence and features of migraine in Japanese junior high school students aged 12-15 yr. Brain Dev 29: 482-485. [Crossref]

3. Barea LM, Tannhauser M, Rotta NT (1996) An epidemiologic study of headache among children and adolescents of southern Brazil. Cephalalgia 16: 545-549. [Crossref]

4. Karli N, Akis N, Zarifoglu M, Akgoz S, Irgil E, et al. (2006) Headache prevalence in adolescents aged 12 to 17: a student-based epidemiological study in Bursa. Headache 46: 649-655. [Crossref]

5. Lima M, Padula N, Santos L, Oliveira L, Agapejev S, et al. (2005) Critical analysis of the international classification of headache disorders diagnostic criteria( ICHD I 1988) and (ICHD- II-2004), for migraine in children and adolescents. Cephalalgia 25 1042-1047. [Crossref]

6. Ozge A, Bugdayci R, Sasmaz T, Kaleagasi H, Kurt O, et al. (2002) The sensitivity and specifity of the case definition criteria of headache: a school -based epidemiological study of 5562 children in Mersin. Cephalalgia22:138-145. [Crossref]

7. Pothmann R, Frankenberg SV, Muller B, Sartory G, Hellmeier W (1994) Epidemiology of headache in children and adolescents: evidence of high prevalence of migraine. Int $J$ Behav Med 1: 76-89. [Crossref]

8. Moore AJ, Shevell M (2004) Chronic daily headaches in pediatric neurology practice. $J$ Child Neurol 19: 925-929. [Crossref]

9. Raieli V, Eliseo M, Pandolfi E, La Vecchia M, La Franca G, et al. (2005) Recurren 
Pacheva I (2016) Distribution of chronic or recurrent headache in children and adolescents in two studies - epidemiological study and clinical-based study

and chronic headaches in children below 6 years of age. J Headache Pain 6: 135-142. [Crossref]

10. Raieli V, Eliseo G, La Vecchia M, La Franca G, Pandolfi E, et al. (2002) Idiopathic stabbing headache in the juvenile population: a clinical study and review of the literature. J Headache Pain 3: 21-25. [Crossref]

11. Balottin U, Nicoli F, Pitillo G, Ferrari Ginevra O, Borgatti R, et al. (2004) Migraine and tension headache in children under 6 years of age. Eur J Pain 8: 307-314. [Crossref]

12. Gallai V, Sarchielli P, Carboni F, Benedetti P, Mastropaolo C, et al. (1995) Applicability of the 1988 IHS criteria to headache patients under the age of 18 years attending 21 Italian headache clinics. Headache 35: 146-153. [Crossref]

13. Maytal J, Bienkowski RS, Patel M, Eviatar L (1995) The value of brain imaging in children with headaches. Pediatrics 96: 413-416. [Crossref]
14. Dong Z, Di H, Dai W, Liang J, Pan M, et al. (2012) Application of ICHD-II criteria in a headache clinic of China. PLoS One 7: e50898. [Crossref]

15. Aysun S, Yetük M (1998) Clinical experience on headache in children: analysis of 92 cases. J Child Neurol 13: 202-210. [Crossref]

16. Nevo Y, Kramer U, Rieder-Groswasser I, Harel S (1994) Clinical categorization of 312 children with chronic headache. Brain Dev 16: 441-444. [Crossref]

17. Pascual J, Berciano J (1995) Clinical experience with headaches in preadolescent children. Headache 35: 551-553. [Crossref]

18. Seshia SS (2004) Mixed migraine and tension-type: a common cause of recurrent headache in children. Can J Neurol Sci 31: 315-318. [Crossref]

19. Seshia SS (2004) Chronic daily headache in children and adolescents. Can J Neurol Sci 31: 319-323. [Crossref]

Copyright: ( 2016 Pacheva I. This is an open-access article distributed under the terms of the Creative Commons Attribution License, which permits unrestricted use, distribution, and reproduction in any medium, provided the original author and source are credited. 